\title{
Relics of Hutchins and Fermi linger on
}

\section{Chicago, a city boasting more than its share of Nobel laureates, is a tempting prospect for would-be members of the 'brain-drain'.}

\section{Chicago (March)}

Is the glut of academics about to end? This is the surprising indicator of the academic labour market as seen from the University of Chicago, where the provost, Norman Bradburn, says that it has become increasingly difficult to fill faculty positions with people from the United States, which is why "we're looking closely to Oxford and Cambridge".

The explanation is only partly demographic. The expansion of the US university system after the Second World War, driven by the rights of demobilized servicemen to get themselves a college education, began earlier than in Britain. This means that large numbers of academics will soon be reaching retirement age. So the need for academics, at least at places such as Chicago, remains high. What more natural than to extend recruitment networks to other English-speaking countries where would-be academics are in plentiful supply?

To make seduction simpler, the University of Chicago reckons now to have lived through and recovered from its troubles, in the $1950 \mathrm{~s}$, when it became the surprised victim of the urban blight and social unrest in which it was physically embedded. Then, according to one member of the faculty, the half-life of a newly appointed faculty member was about 150 days. Another explains that people were unwilling to travel away to meetings if their wives were required to stay behind. But now urban blight has been beaten back by the university's deliberate involvement in urban development, so that 90 per cent of the faculty are now able to walk to work.

The campus is even better known as the place at which Fermi built a nuclear reactor (the first) in a squash court without telling the university president what he was about. The spot is now marked by a Henry Moore sculpture whose symbolism remains a matter for academic conjecture. A more direct legacy is the Enrico Fermi Institute, physically an evidently 1940 s building but intellectually a kind of living museum of Fermi's enthusiasms - cosmic rays, isotope chemistry and particle physics, for example.

But Fermi's post-war cyclotron has been dismantled and the hangar-like space that housed it cannibalized for the building of particle detectors for use at Fermilab (the National Accelerator Laboratory at Batavia, the other side of the city); in one corner is a shed (to keep out dust) housing a detector of primary cosmic rays returned from one of the earlier shuttle flights and waiting for another chance to fly.

Chicago is also the private university (outside the Ivy League) at which, between 1929 and 1951, Robert M. Hutchins made his name as a distinctive university president, most memorably as an advocate and practitioner of a broad liberal arts education as a foundation of all curricula. Hutchins' legacy is not as easily identified as Fermi's, but it remains. Undergraduates in their first two years must follow courses in each of the physical, biological and social sciences and in the humanities, learn a foreign language and some mathematics (but the calculus is about to give

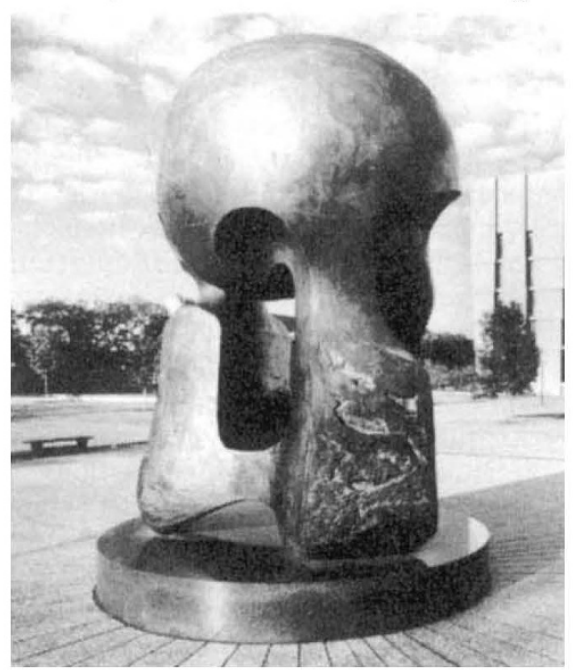

Conjectural symbolism

way to 'quantitative reasoning') as well as a course in civilization. But the reading of Hutchins's Great Books (with Adler) has been abandoned as unteachable. In some respects, the cry is "Long Live Hutchins! Hutchins is dead!".

But Hutchins' interdisciplinarity conspicuously remains. Cosmochemist Edward Anders, formally of the Chemistry Department, might elsewhere be labelled a physicist or even a geologist. Astronomy and astrophysics seem to be part of a seamless web including physics. Albert V. Crewe, building an electron microscope that he reckons will have a resolution of 0.5 angstrom (thanks to the clever design of a sextupole magnetic lens) has biologist Serge N. Vinogradov writing programs for the computer equipment that is a large part of the $\$ 1$ million grant from IBM with which the microscope is being built. The principle seems to be that it is more prudent that a department should acquire critical masses of able people than to attempt to cover the whole of what would conventionally be called its field.

Hutchins' liberalism also shows in the university's declared policy of what it calls "needs-blind" admissions policies. The boast is that nobody considers how much a student will contribute towards tuition costs when considering applications. One consequence is that Chicago's spending out of its own resources on scholarships and fellowships has increased to more than a fifth of the total. Another is that the cost of tuition has risen steeply, from $\$ 9,600$ last academic year to $\$ 12,000$ next.

There are other clouds on the horizon. One product of the troubles of the $1950 \mathrm{~s}$ and 1960s was the analysis that the university had grown too quickly; the response, according to provost Bradburn, was to "shrink a little", but by the 1980 s the university was alarmed that the numbers of graduate students had fallen, "precipitously" in some departments, physics for example. In 1982, a Commission on Graduate Education decided that the explanation was not demographic and recommended various remedies, some educational and some administrative.

On balance, the changes appear to have worked. Graduate recruitment has improved in the departments that formerly lagged behind. After the earlier shrinkage, it is also planned to increase the intake from high schools to reach a total of 3,400 undergraduates (compared with close on 3,000 now) without a corresponding increase of the faculty strength (just over 1,100 ). The result should be a total student body of some 10,000 , divided roughly three ways between undergraduates, graduate students and students in the professional schools.

Surprisingly, given its research record (from Michelson, Arthur Compton and Mulliken in the old days to Chandrasekhar still), the university is also worried about research income, which amounted to $\$ 62.4$ million from federal agencies in 1985-86 (together with $\$ 28.1$ million in indirect or overhead costs). This is a smaller proportion of the total educational budget (just over $\$ 250$ million) than it might be, but Bradburn is especially concerned that Chicago, which does not have an engineering school, will be the loser at a time when federal agencies are increasingly concerned with engineering research. Perhaps a little late in the day, the university has just started a computer science department. It is far from being the only excellent institution in the United States now suddenly more anxious about its future than for 30 years. John Maddox 